Supporting Information

\title{
Liquid-Metal-Assisted Deposition and Patterning of Molybdenum Dioxide at Low Temperature
}

Yifang Wang, ${ }^{a}$ Mohannad Mayyas, ${ }^{* a}$ Jiong Yang, ${ }^{a}$ Mohammad B. Ghasemian, ${ }^{a}$ Jianbo Tang, ${ }^{a}$ Maedehsadat Mousavi, ${ }^{a}$ Jialuo Han, ${ }^{a}$ Mostak Ahmed, ${ }^{a}$ Mahroo Baharfar, ${ }^{a}$ Guangzhao Mao, ${ }^{a}$ Yin Yao, ${ }^{b}$ Dorna Esrafilzadeh, ${ }^{c}$ David Cortie, ${ }^{d}$ Kourosh Kalantar-Zadeh ${ }^{* a}$

${ }^{\text {a }}$ School of Chemical Engineering, University of New South Wales (UNSW), Sydney

Campus, NSW 2052, Australia

${ }^{\mathrm{b}}$ Electron Microscope Unit, University of New South Wales (UNSW), Sydney Campus, Sydney, New South Wales 2052, Australia

${ }^{\mathrm{c}}$ Graduate School of Biomedical Engineering, University of New South Wales (UNSW), Sydney Campus, Sydney, New South Wales 2052, Australia

${ }^{\mathrm{d}}$ Australian Institute for Innovative Materials, Institute for Superconducting and Electronic Materials, University of Wollongong, Innovation Campus Squires Way, North Wollongong, NSW 2522, Australia

Corresponding E-mail: k.kalantar-zadeh@unsw.edu.au,m.mayyas@unsw.edu.au 


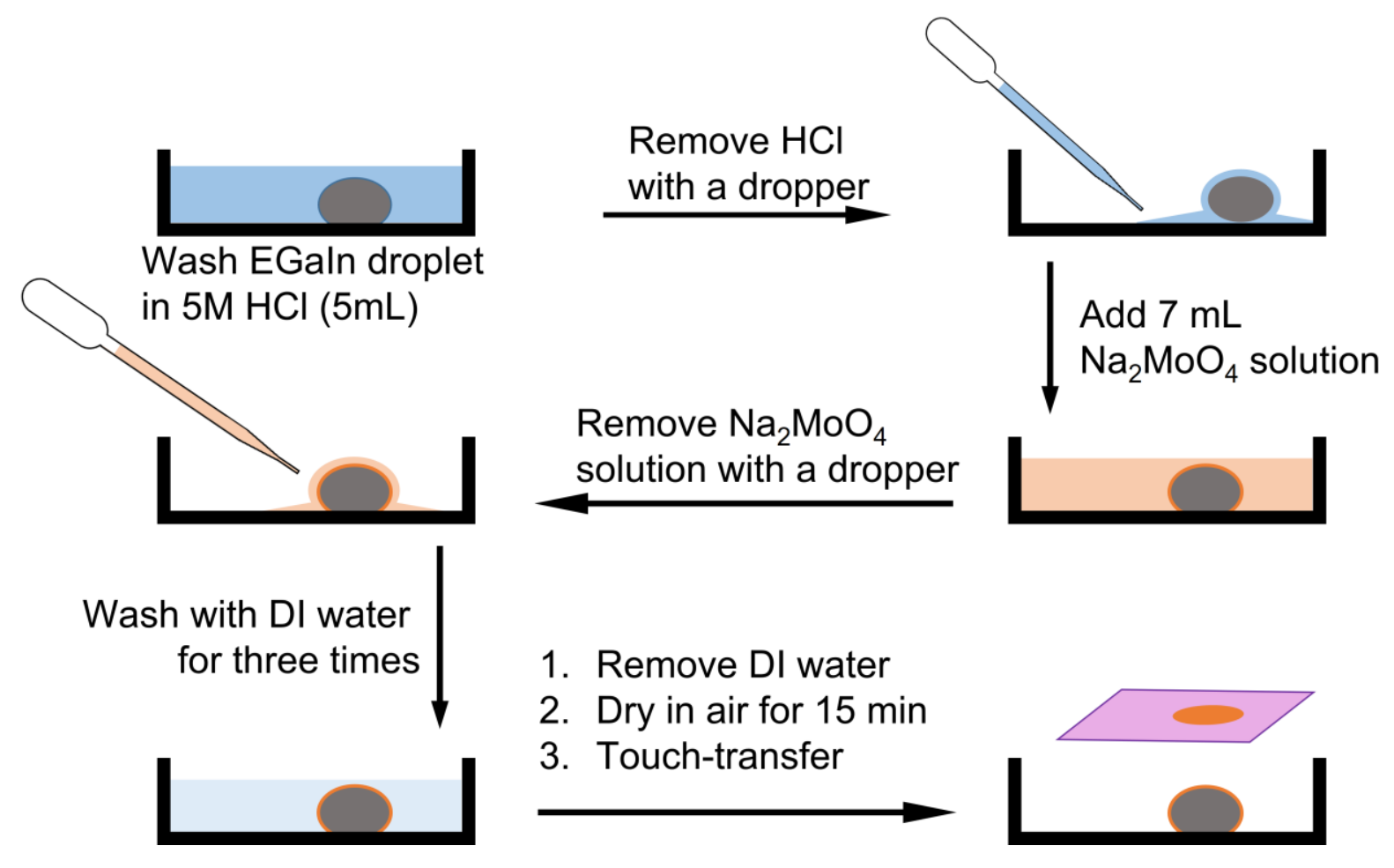

Figure S1. Schematic illustration of the synthesis process of $\mathrm{H}_{2} \mathrm{MoO}_{3}$.
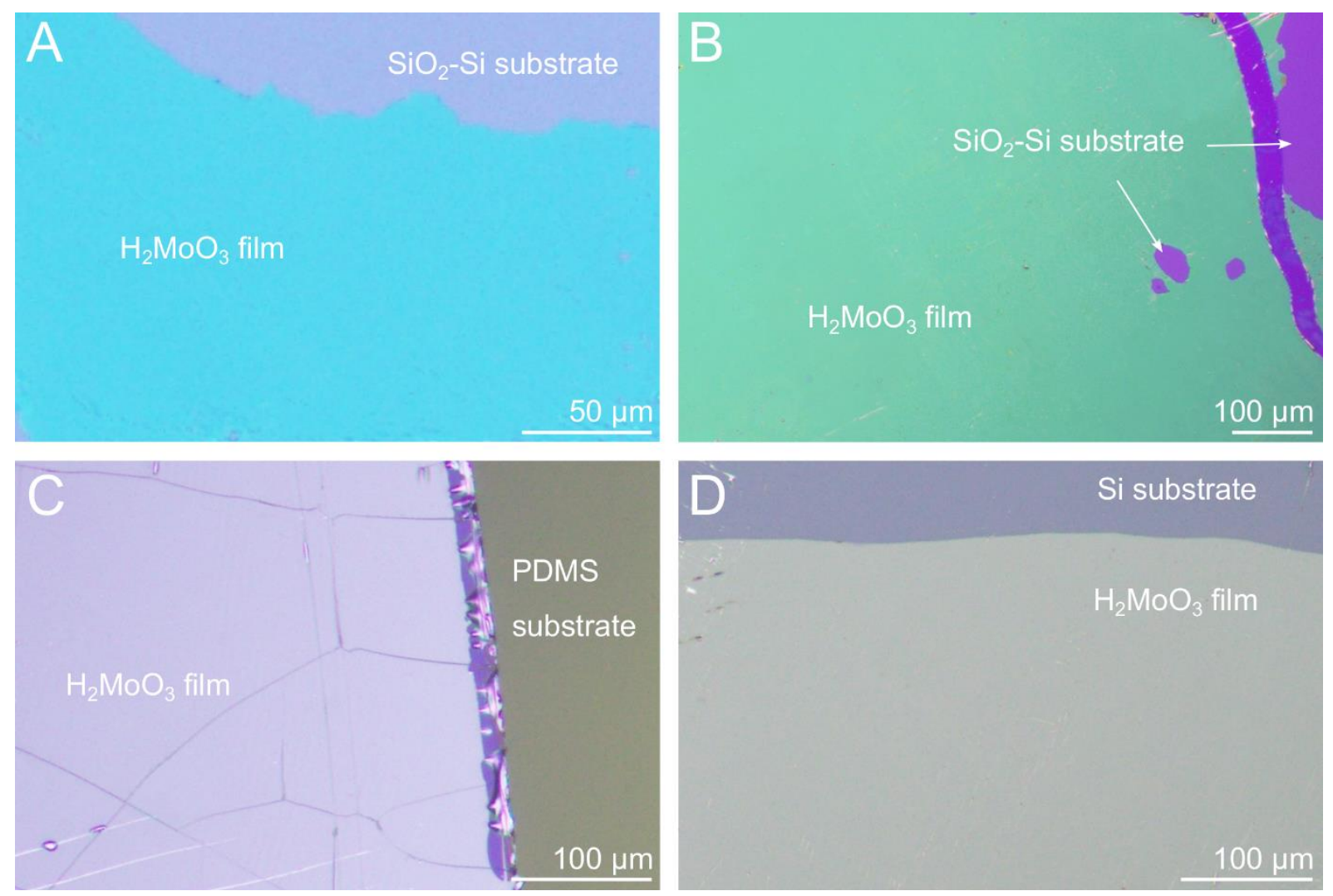

Figure S2. Optical microscopy images of transferred $\mathrm{H}_{2} \mathrm{MoO}_{3}$ film on (A) and (B) Si-SiO2 substrate, (C) PDMS substrate and (D) Si Substrate. 


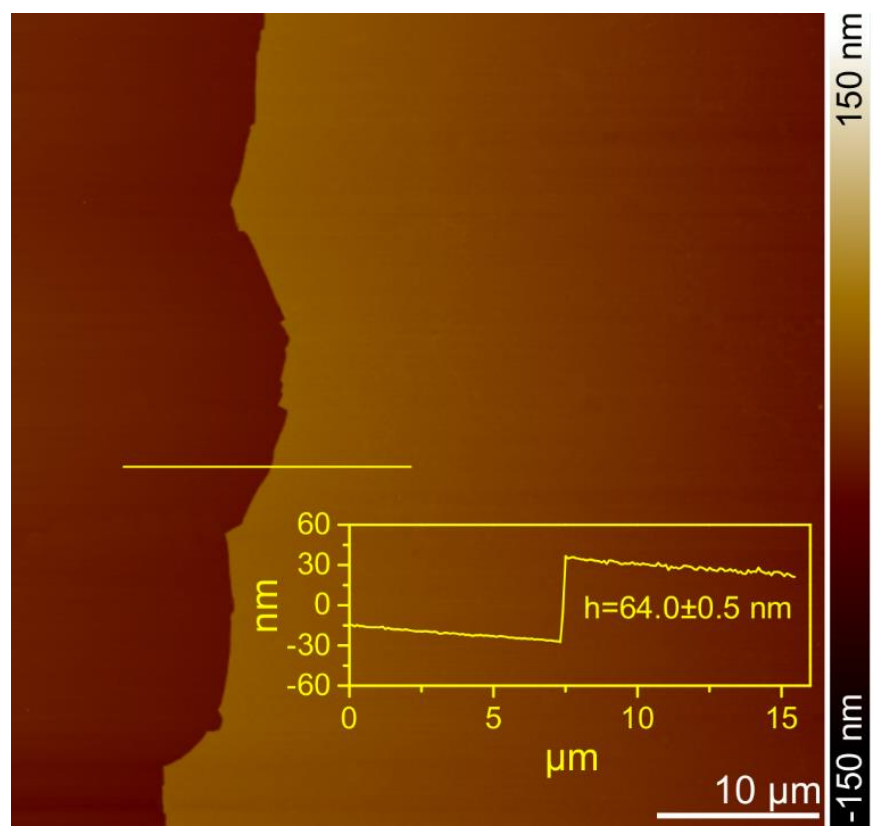

Figure S3. An AFM image of $\mathrm{H}_{2} \mathrm{MoO}_{3}$ films.
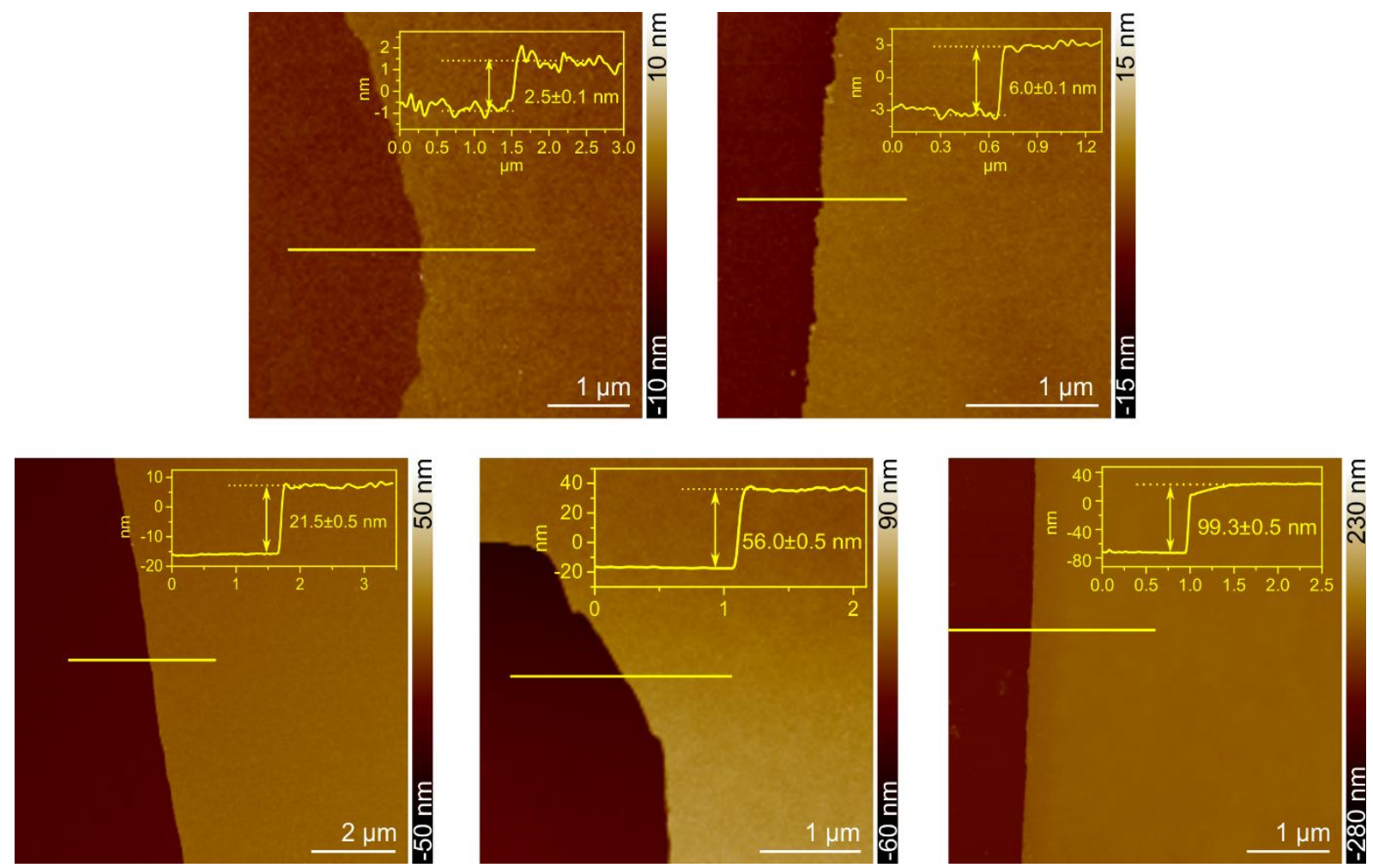

Figure S4. AFM images of $\mathrm{H}_{2} \mathrm{MoO}_{3}$ films of different thickness. 


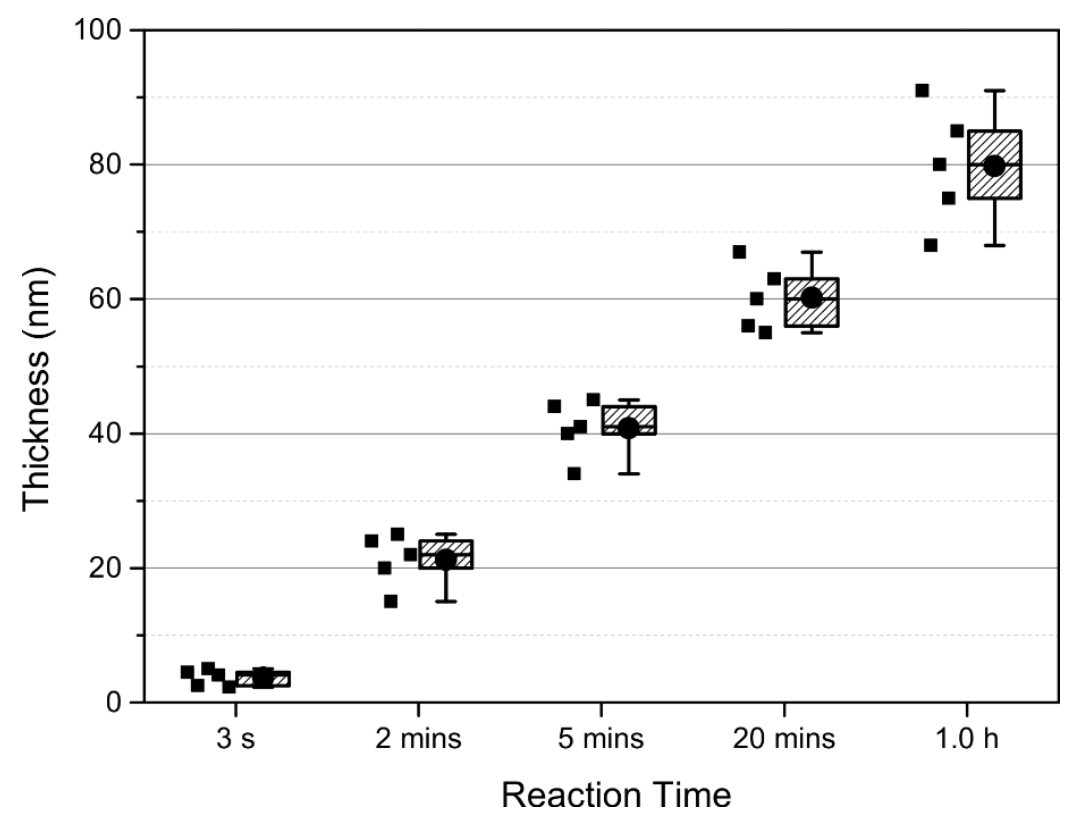

Figure S5. The box chart presenting the thickness distribution of materials yield at different reaction time ( $3 \mathrm{~s}, 2$ mins, 5 mins, 20 mins, $1.0 \mathrm{~h})$.

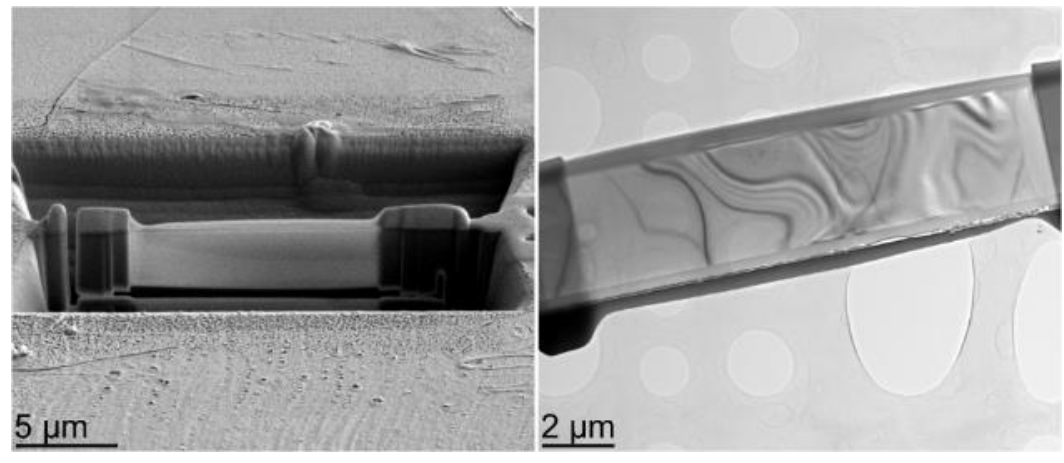

Figure S6. SEM-FIB, zoomed out and the 45 degree picture during FIB.

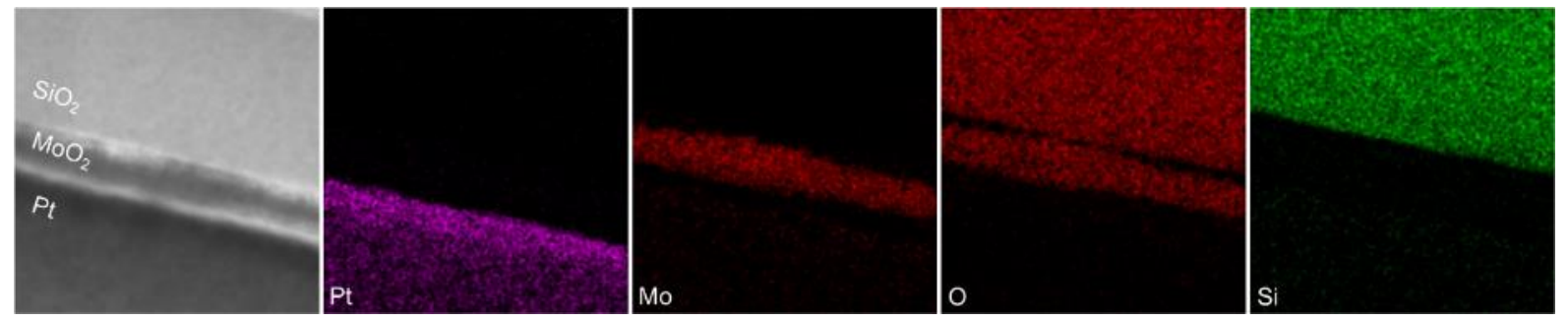

Figure S7. EDS mapping of the TEM sample. 

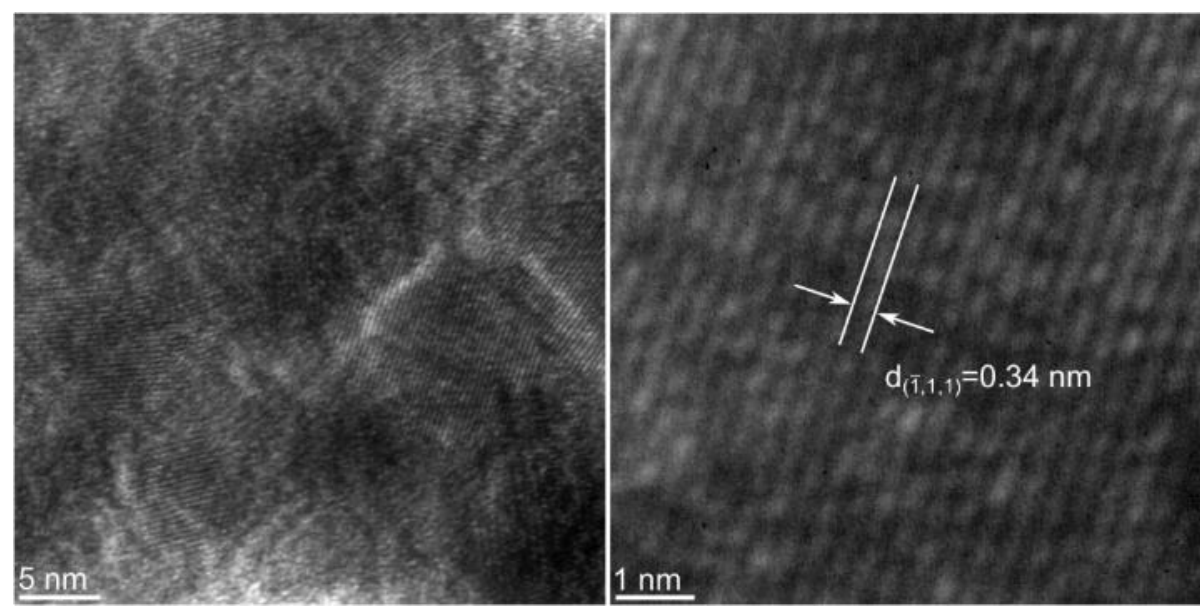

Figure S8. High-resolution TEM images of the thermo-annealed $\mathrm{MoO}_{2}$.
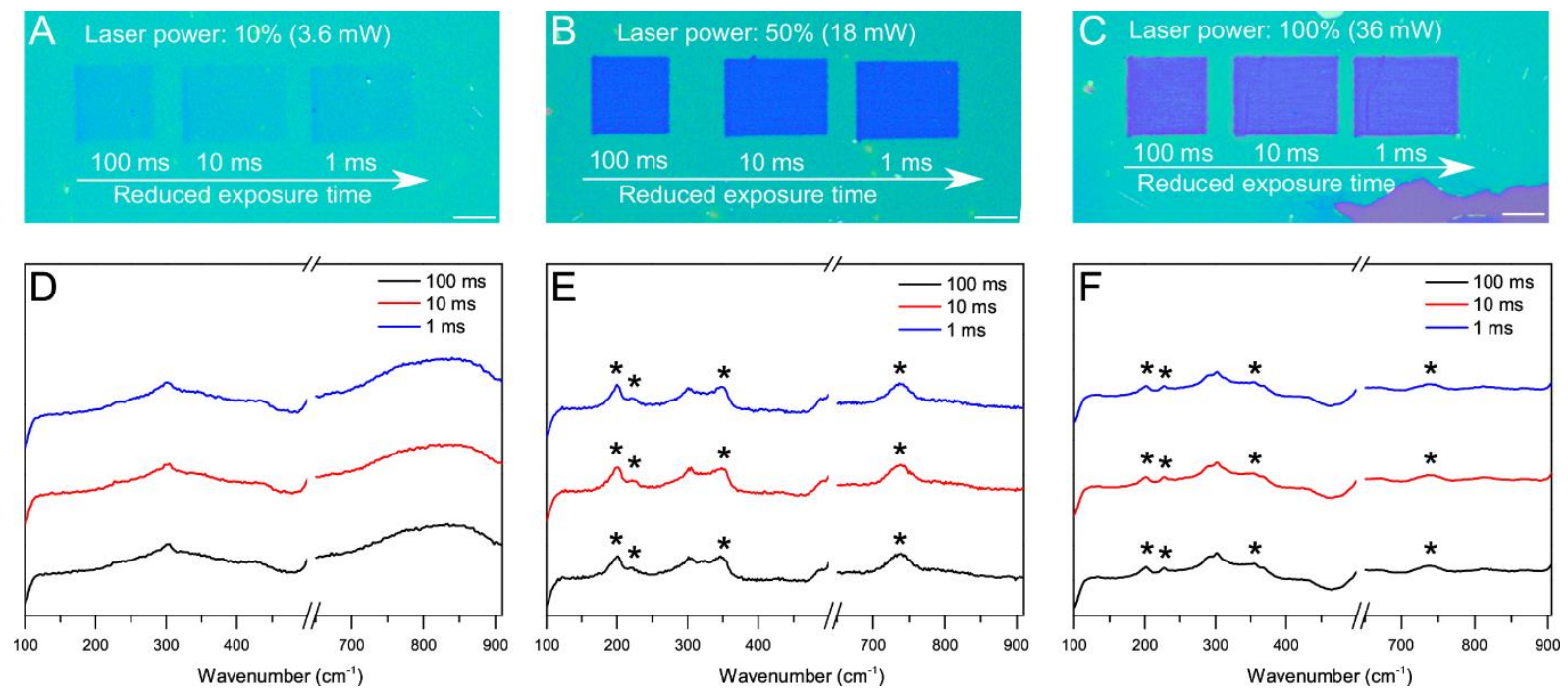

Figure S9: Optical images and Raman spectra of materials annealed at different laser powers and exposure times. (A-C): Optical images of materials acquired at 10\%, 50\%, and $100 \%$ laser powers, respectively. (D-F): Raman spectra of materials acquired at 10\%, 50\%, and $100 \%$ laser powers, respectively. Characteristic peaks of $\mathrm{MoO}_{2}$ were marked with stars. 


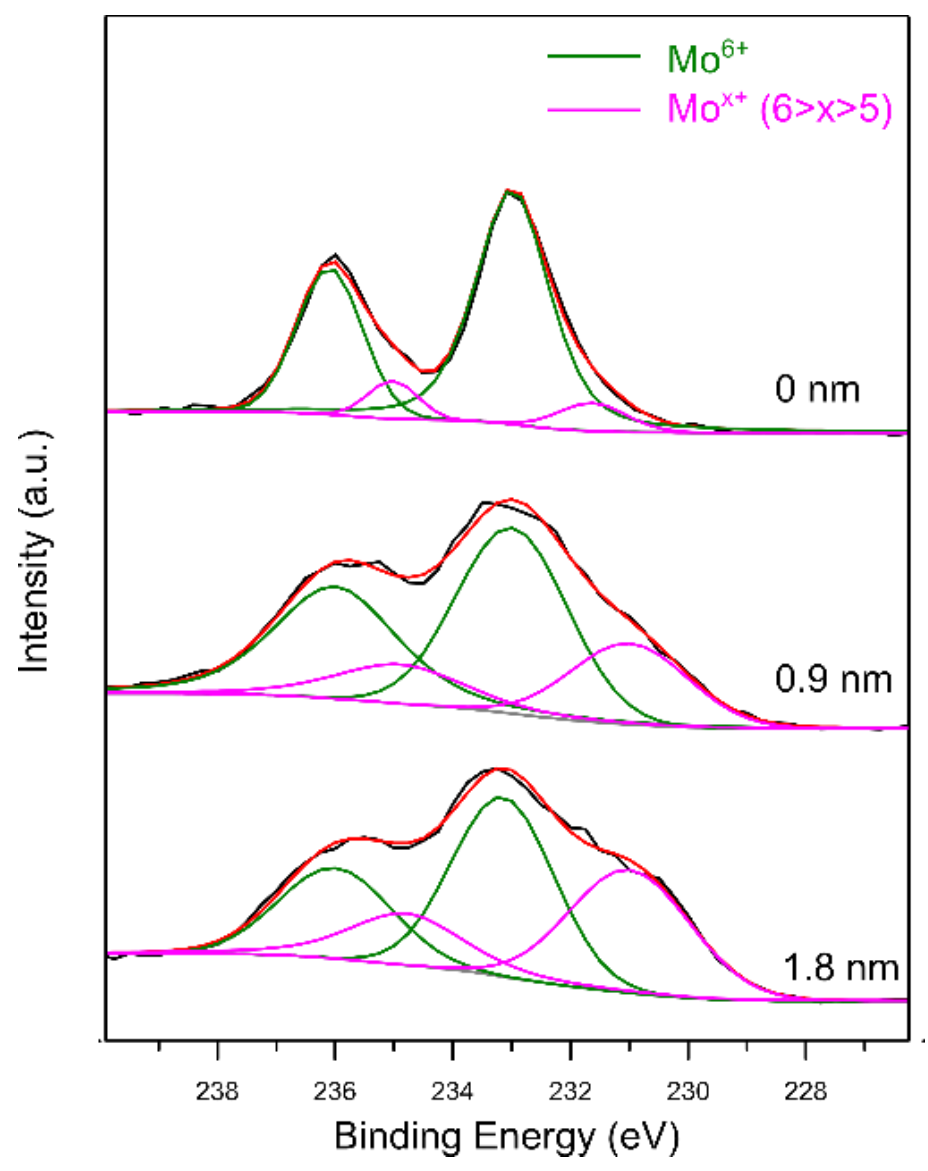

Figure S10. Peak fitting of the high-resolution XPS of the surface of the laser-annealed $\mathrm{MoO}_{2}$ film (depth 0- $1.8 \mathrm{~nm})$.

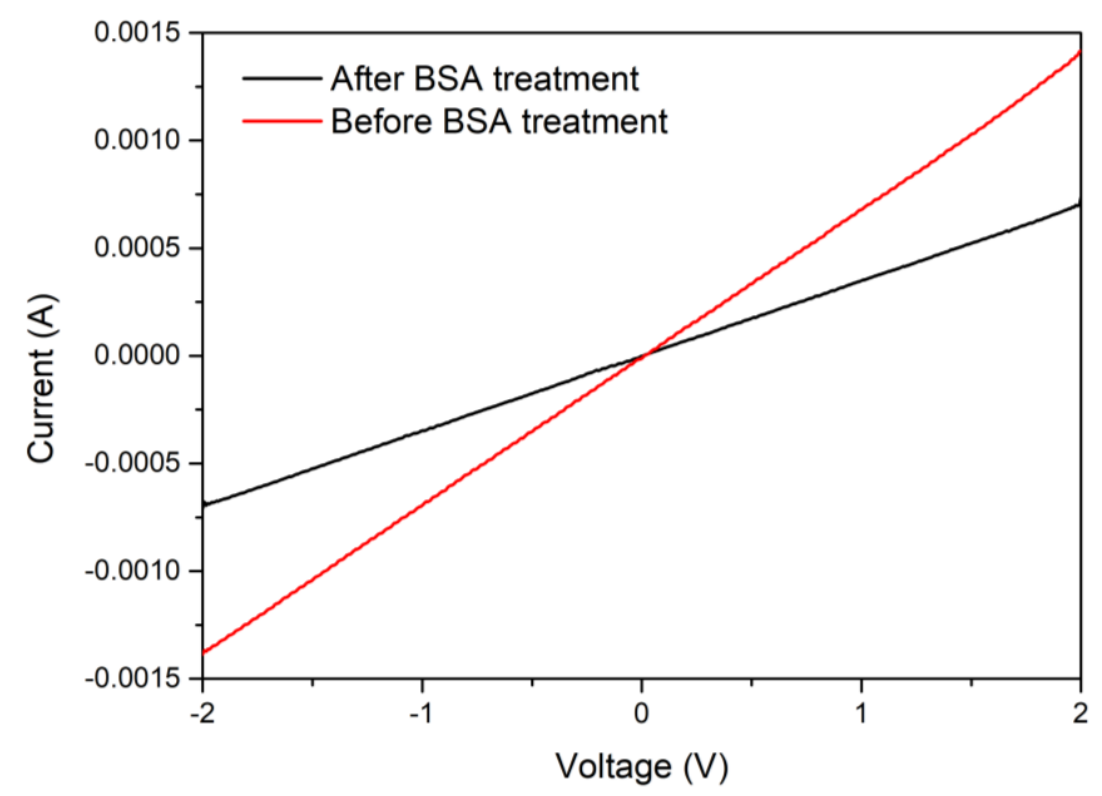

Figure S11. I-V curves of the $\mathrm{MoO}_{2}$ based device before and after the BSA treatment. 


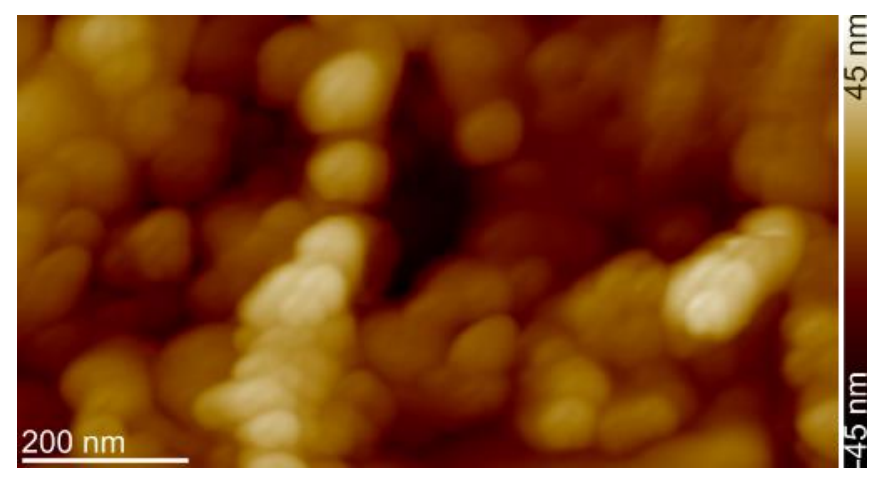

Figure S12. High resolution AFM topography of the laser annealed sample.

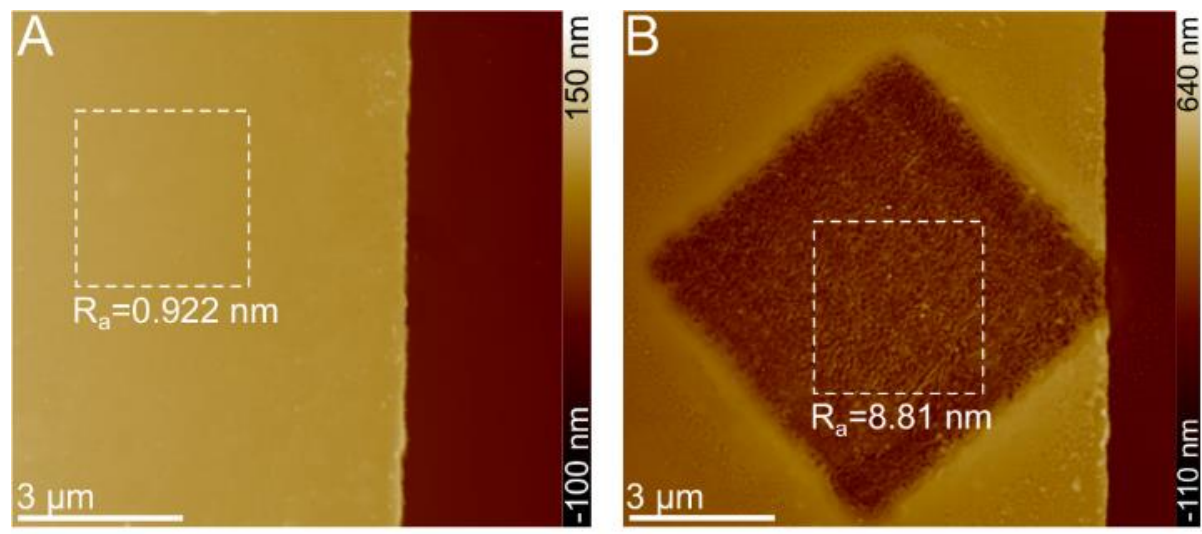

Figure S13. Roughness calculations based on AFM imaging of the a sample (A) before and (B) after laser patterning. 
A

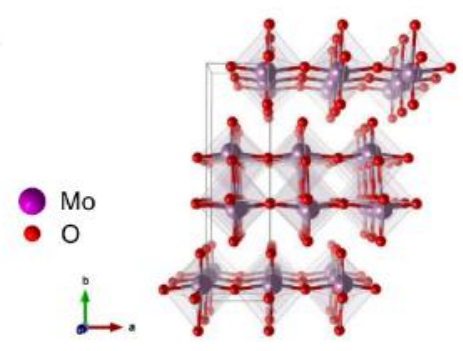

B

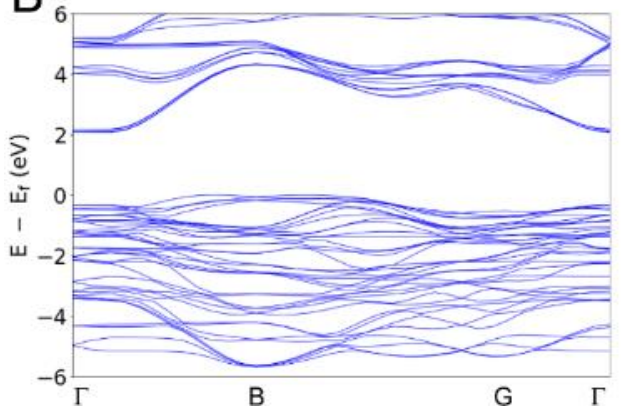

C
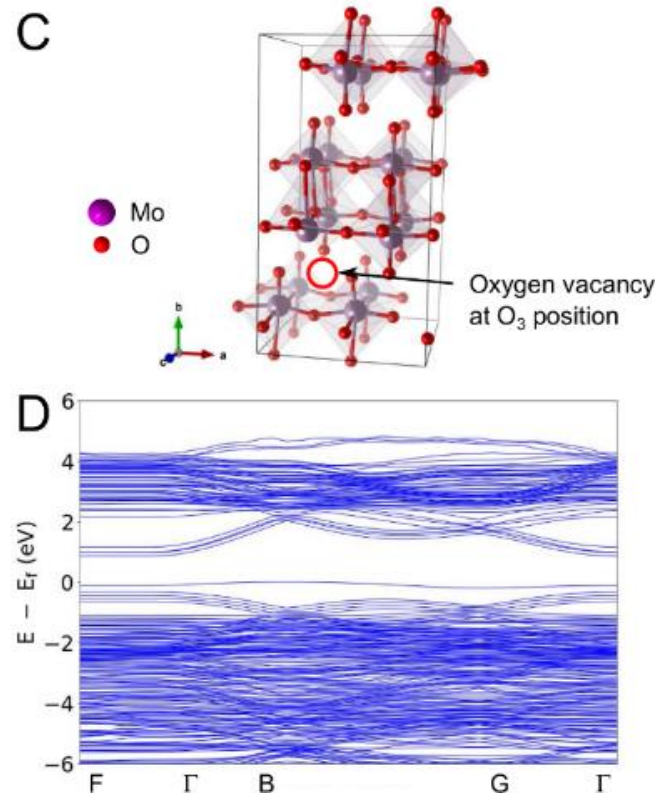

Figure S14. (A and B) Crystal structure and band structure of 3D $\mathrm{MoO}_{3}$. (C and D) Crystal structure and band structure of $3 \mathrm{D} \mathrm{MoO}_{3}$ with an oxygen vacancy.

A

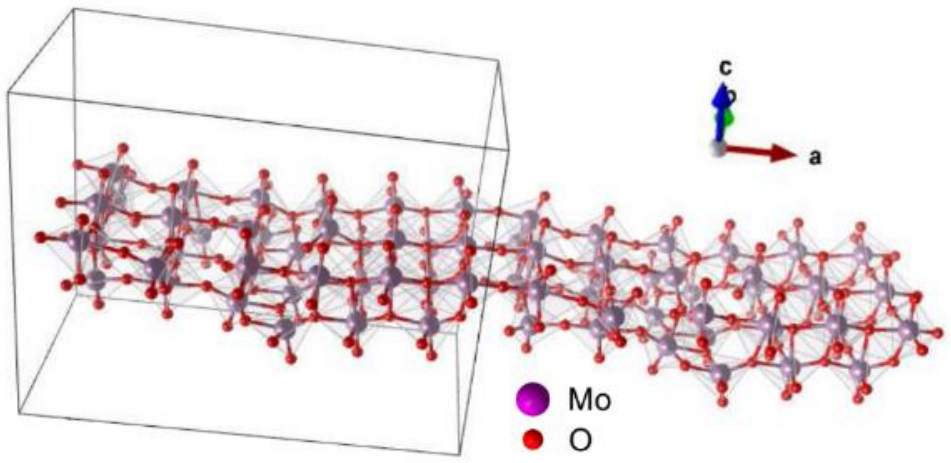

B

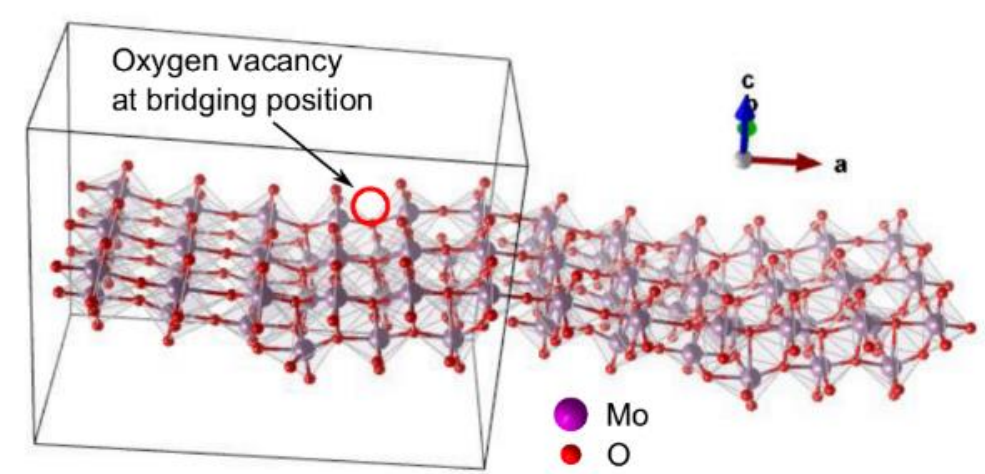

Figure S15. (A) Structure of the modelled grain boundary of 2D $\mathrm{MoO}_{3}$. (B) Structure of the modelled grain boundary of the $2 \mathrm{D} \mathrm{MoO}_{3}$ with oxygen vacancy at bridging oxygen position. 

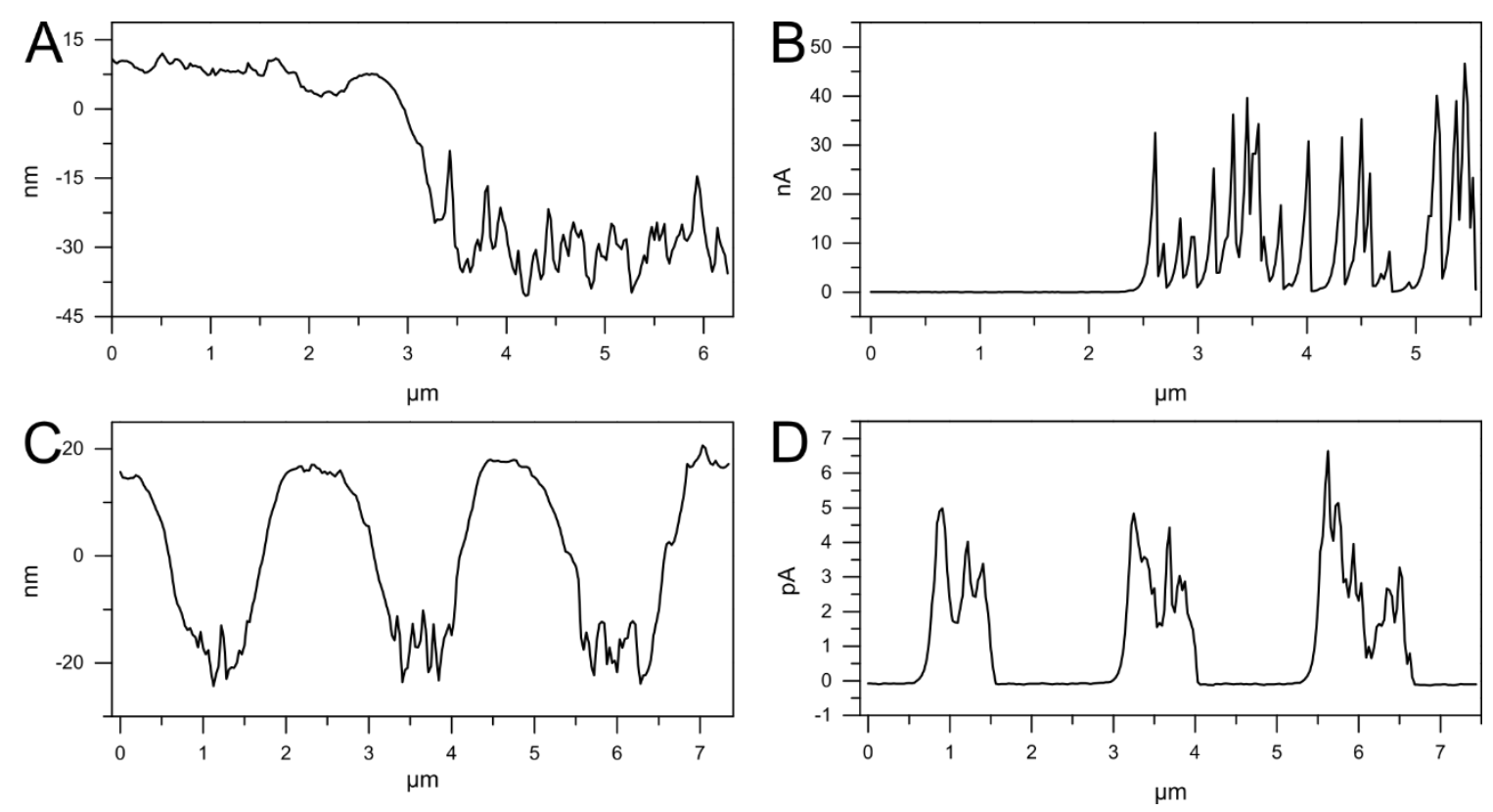

Figure S16. (A) Height profile of Figure 6D. (B) Current profile of Figure 6E. (C) Height profile of Figure 6H. (D) Current profile of Figure 6I. 

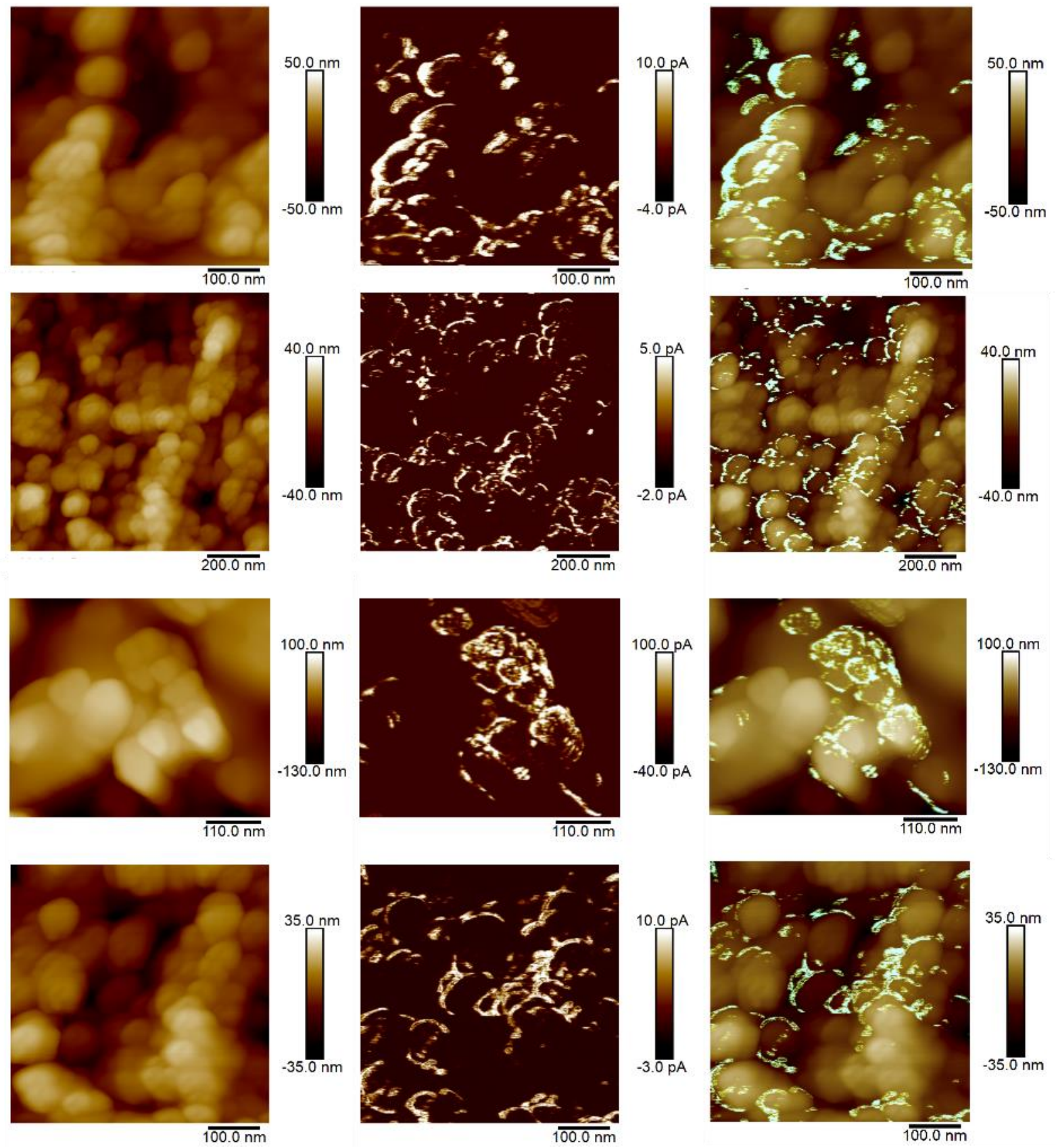

Figure S17. Further high-resolution PF-TUNA measurements. Left column: height profiles.

Middle column: current profiles. Right column: the overlapped images of morphology and current signals. 


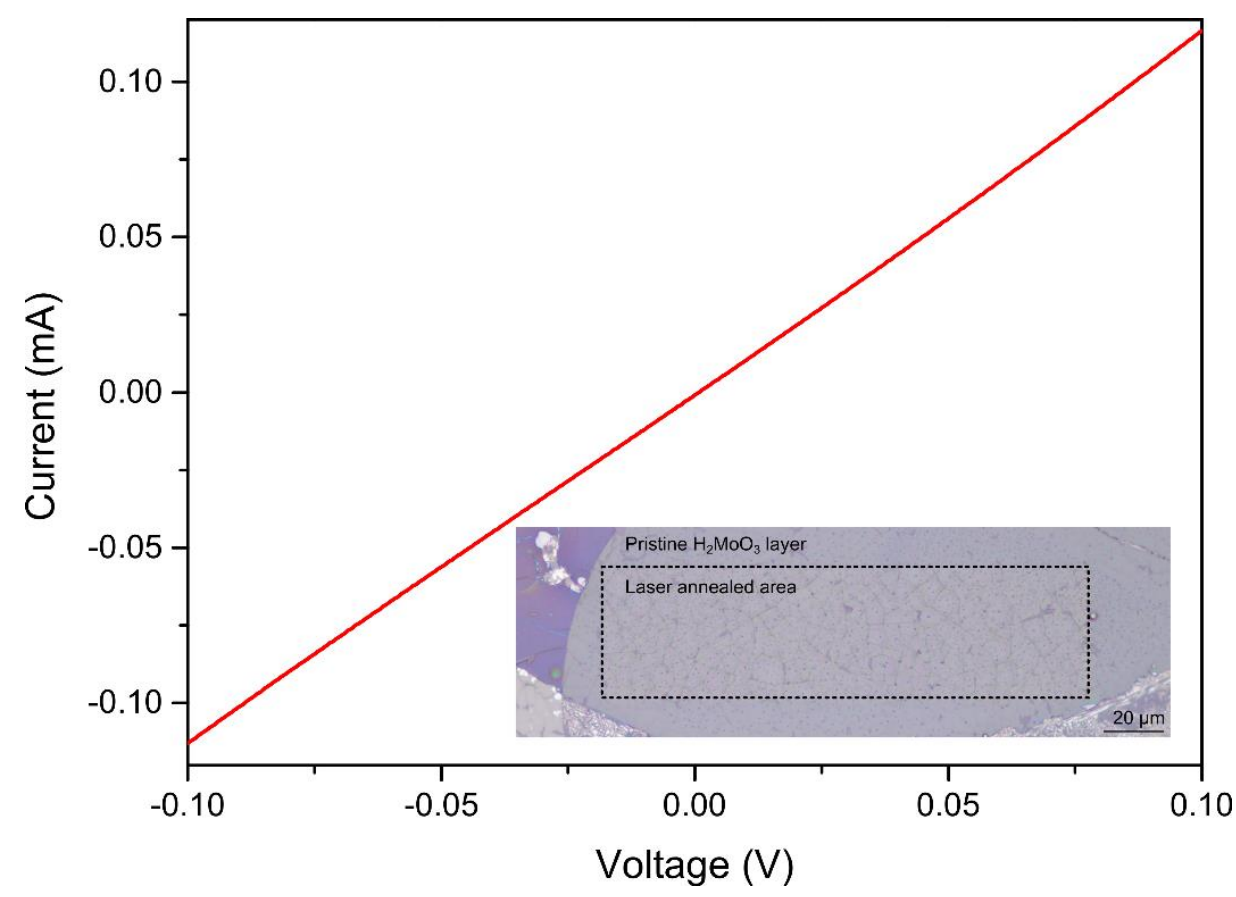

Figure S18. The I-V curve of the laser annealed $\mathrm{MoO}_{2}$ on PDMS, with an example optical microscopy image of the laser annealed $\mathrm{MoO}_{2}$ on PDMS inserted.

Table S1. The sample dimensions and resistance data used for conductivity calculations of samples of laser annealed materials on different substrate.

\begin{tabular}{|c|c|c|c|c|c|c|}
\hline Substrate & $\begin{array}{c}\text { Length } \\
(\mathrm{cm})\end{array}$ & $\begin{array}{c}\text { Thickness } \\
(\mathrm{nm})\end{array}$ & $\begin{array}{c}\text { Width } \\
(\mathrm{cm})\end{array}$ & $\begin{array}{c}\text { Area } \\
\left(\mathrm{cm}^{2}\right)\end{array}$ & $\begin{array}{c}R \\
(\Omega)\end{array}$ & $\begin{array}{c}\sigma \\
\left(\mathrm{S} \mathrm{cm}^{-1}\right)\end{array}$ \\
\hline $\mathrm{PDMS}$ & 0.39 & 58 & 0.191 & $1.11 \times 10^{-6}$ & 891.3 & 395.0 \\
\hline $\mathrm{Si}$ & 0.51 & 37 & 0.060 & $2.41 \times 10^{-7}$ & 5089.1 & 416.7 \\
\hline $\mathrm{SiO}_{2} / \mathrm{Si}$ & 0.35 & 46 & 0.115 & $5.29 \times 10^{-7}$ & 1769.4 & 373.9 \\
\hline
\end{tabular}

